JAN 021997

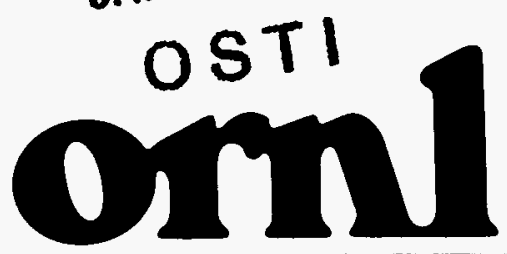

ORNL/TM-13339

A SIMPLE ROTATIONAL PENDULUM METHOD TO MEASURE THE RADI OF GYRATION OR MASS MOMENTS OF INERTIA OF A ROTOR AND OTHER ASSEMBLIES

NATIONAL LABORATORY

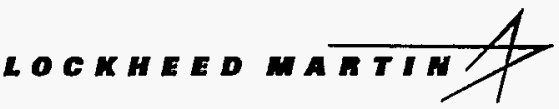

John B. Andriulli

Oak Ridge National Laboratory
MANAGED AND OPERATED BY LOCKHEED MARTH ENERGY RESEARCH CORPORATION FOR THE UNTED STATES DEPARTMENT OF ENERGY
Prepared by the Oak Ridge National Laboratory Oak Ridge, Tennessee 37831

Managed by Lockheed Martin Energy Research Corporation for the U. S. Department of Energy under Contract No. DE-AC05-96OR22464

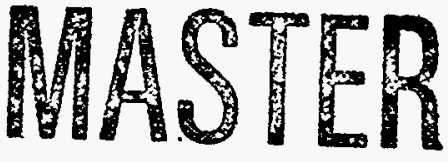


This report has been reproduced directly from the best available copy.

Available to DOE and DOE contractors from the Office of Scientific and Technical Information, Post Office Box 62, Oak Ridge, Tennessee 37831; prices available from (423) 576-8401.

Available to the public from the National Technical Information Service, U.S. Department of Commerce, 5285 Port Royal Road, Springfield, Virginia 22161.

This report was prepared as an account of work sponsored by an agency of the United States Government. Neither the United States Government nor any agency thereof, nor any of their employees, makes any warranty, express or implied, or assumes any legal liability or responsibility for the accuracy, completeness, or usefulness of any information, apparatus, product, or process disclosed, or represents that its use would not infringe privately owned rights. Reference herein to any specific commercial product, process, or service by trade name, trademark, manufacturer, or otherwise, does not necessarily constitute or imply its endorsement, recommendation, or favoring by the United States Government or any agency thereof. The views and opinions of authors expressed herein do not necessarily state or reflect those of the United States. 


\title{
A SIMPLE ROTATIONAL PENDULUM METHOD TO MEASURE THE RADII OF GYRATION OR MASS MOMENTS OF INERTIA OF A ROTOR AND OTHER ASSEMBLIES
}

\author{
John B. Andriulli \\ Oak Ridge National Laboratory
}

Prepared by the Oak Ridge National Laboratory

Oak Ridge, Tennessee 37831

Managed by

Lockheed Martin Energy Research Corporation for the

U. S. Department of Energy

under Contract No. DE-AC05-96OR22464 


\section{DISCLAIMER}

Portions of this document may be illegible in electronic image products. Images are produced from the best available original document. 


\title{
A SIMPLE ROTATIONAL PENDULUM METHOD TO MEASURE THE RADII OF GYRATION OR MASS MOMENTS OF INERTIA OF A ROTOR AND OTHER ASSEMBLIES
}

\author{
John B. Andriulli \\ Oak Ridge National Laboratory \\ Oak Ridge, Tennessee 37831-8088
}

\section{INTRODUCTION}

In mechanical dynamic problems, it is often necessary to know the radii of gyration or equivalent mass moments of inertia of components and assemblies. Using the rotational pendulum technique described, one can easily measure the radii of gyration about the polar and diametric axes of any rigid rotor without requiring a special fixture. The principals employed are also applicable to more complicated assemblies such as aircraft, boats, and cars, where the radius of gyration and vehicle maneuverability are of interest. This description focuses on rotors.

The relative values of polar and diametric radii of gyration characterize some dynamic behavior and stability of spinning rotors. When the ratio of polar to diametric radii of gyration approaches unity, the spinning rotor may exhibit undesirable dynamic behavior. Consequently, prior to high-speed spin testing the rotor or otherwise operating the assembly, it is desirable to have a simple and inexpensive procedure to directly measure the radii of gyration of existing hardware. These data permit the technician to estimate the rotor dynamic behavior or identify potential problems prior to committing to operation.

If sufficient part information is available, such as dimensions, geometry and material density, one can calculate the radii of gyration. For complicated parts, this can be time consuming. Often the technician does not have access to the rotor's dimensional details to make the calculations. Hence, an inexpensive empirical technique such as the one described is valuable.

\section{PROCEDURE}

The procedure makes use of measuring the natural frequency and key dimensions of a rotational pendulum formed by hanging the rotor on wires of negligible mass. From these measured parameters, the radii of gyration is computed using the simple natural frequency formula described below.

A typical rotational pendulum arrangement for measuring the polar radius of gyration is shown in Fig. 1a. Typical arrangements for measuring the diametric radius of gyration are shown in Figs. $1 \mathrm{~b}$ and $1 \mathrm{c}$. Either diametric arrangement (Figs. $1 \mathrm{~b}$ or $1 \mathrm{c}$ ) can be used. The choice is a matter of convenience depending upon the rotor configuration. To calculate high- 
speed rotor behavior, it is necessary to know both the polar and diametric radii of gyration.

In all cases, the pendulum wires should be parallel, have equal length $(\mathrm{L})$, be equidistant $(\mathrm{r})$ from the rotor's center of gravity, and should share the rotor weight equally. Often, the center of gravity can be determined by geometric symmetry or by balancing the rotor on a knife edge or from a wire. The lengths $\mathrm{L}$ and $\mathrm{r}$ should be chosen such that errors in measuring length are negligible and that the pendulum natural frequency oscillations can be timed with a stop watch. Usually oscillations with natural frequency in the 0.2 to $2 \mathrm{~Hz}$ range can be easily counted and timed.

Pendulum oscillations are started with an initial rotational displacement (up to 10 degrees single amplitude) then released such that the small-angle linearization assumption is valid. Since damping is usually small, tens of oscillations of approximately equal amplitude can be counted and timed giving an accurate and repeatable estimate of pendulum natural frequency.

The measured natural frequency $(\mathrm{f})$ in $\mathrm{Hz}$ is determined as

$$
\mathrm{f}=\frac{\mathrm{n}}{\mathrm{t}} \text {, }
$$

where

$$
\begin{aligned}
& \mathrm{n}=\text { number of cycles } \\
& \mathrm{t}=\text { time for } \mathrm{n} \text { cycles, } \mathrm{s} .
\end{aligned}
$$

The linearized differential equation of motion for the rotational pendulum is given by

$$
\frac{\mathrm{d}^{2} \theta}{\mathrm{dt}^{2}}+\frac{\mathrm{r}^{2} \mathrm{~g}}{\mathrm{k}^{2} \mathrm{~L}} \theta=0
$$

where

$\theta=$ angular displacement the wire makes with the vertical, rad

$\mathrm{L}=$ length of pendulum wire, in.

$r=$ distance of the rotor center of gravity to the wire, in.

$\mathrm{g}=$ local gravitational acceleration, $\left(\sim 386.4 \mathrm{in} . / \mathrm{s}^{2}\right)$

$\mathrm{k}=$ radius of gyration, in. 
The solution to the differential equation yields the natural frequency (f) in $\mathrm{Hz}$ of the rotational pendulum as

$$
f=\frac{1}{2 \pi} \sqrt{\frac{r^{2} g}{k^{2} L}},
$$

from which the radius of gyration can be calculated as

$$
k=\frac{r}{2 \pi f} \sqrt{\frac{g}{L}} .
$$

The mass moment of inertia (I) is obtained from the measured rotor weight (w), using the classical definition of mass moment of inertia.

$$
\mathrm{I}=\frac{\mathrm{w}}{\mathrm{g}} \mathrm{k}^{2} .
$$

\section{EXAMPLE}

For the measured parameters $L=30$ in., $r=5$ in., $n=10, t=10 \mathrm{~s}$, and $w=10 \mathrm{lb}$, the natural frequency $f=1 \mathrm{~Hz}$, the radius of gyration $k=2.856 \mathrm{in}$., and the mass moment of inertia $I=0.211 \mathrm{lb}-\mathrm{in}_{\mathrm{s}} \mathrm{s}^{2}$.

Time saver: To ensure reasonable oscillation count and timing for a specific rotor, guess at a value for radius of gyration $\mathrm{k}$ and use the frequency equation to determine trial values for lengths $L$ and $r$ before initiating the test setup.

\section{CONCLUSION}

The rotational-pendulum technique is an inexpensive and accurate method to determine radii of gyration of rotors. The advantages of the rotational pendulum method are a) no rotorspecific adapters or fixtures, b) no special instrumentation, c) quick and simple setup and measurements, and d) good accuracy depending upon length and frequency measurements. The method is also applicable to other complex structures as long as the structure can be appropriately suspended as a rotational pendulum. 


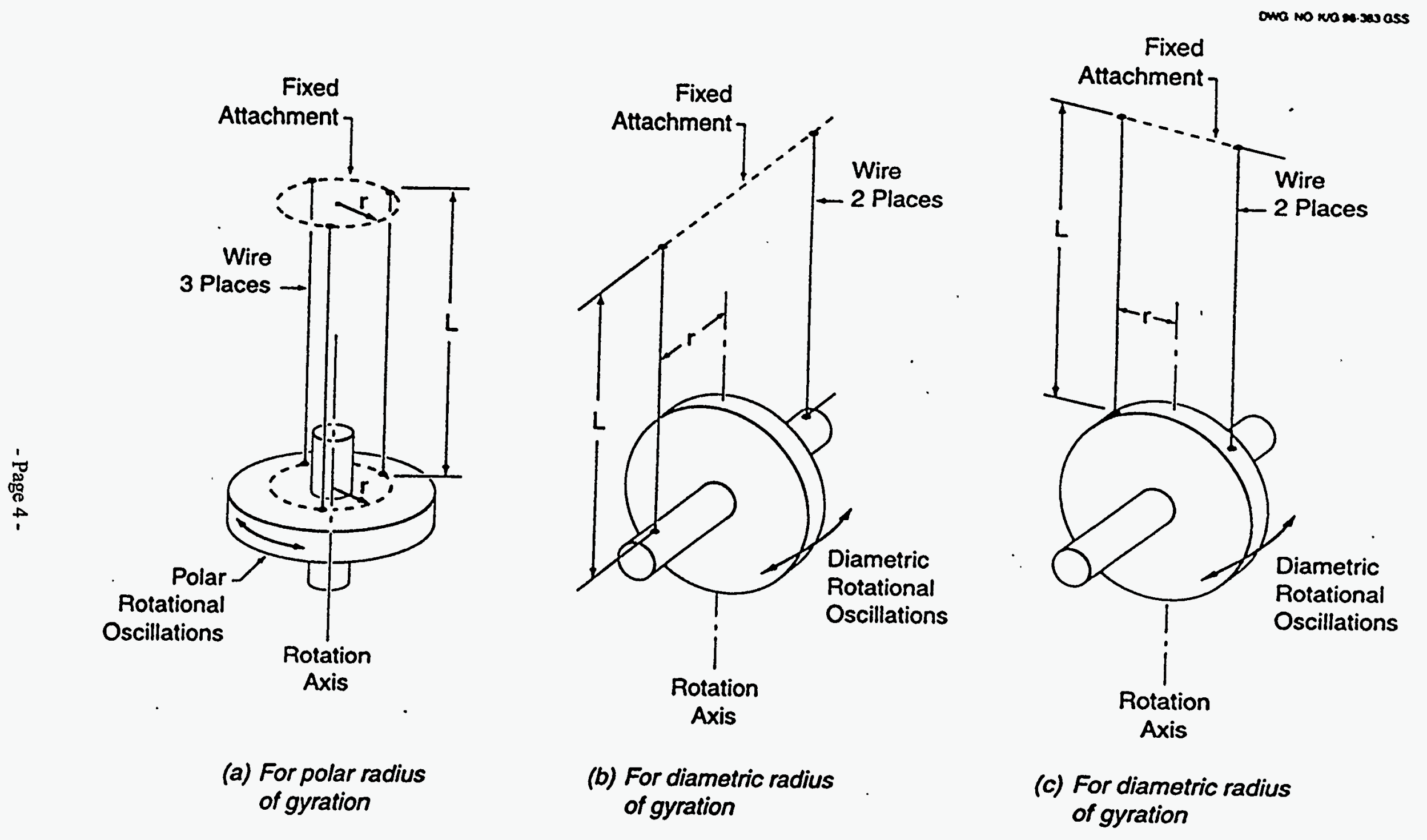

Fig. 1. Typical rotational pendulum arrangèments for measuring the radii of gyration of a rotor. 
ORNL/TM-13339

\section{Internal Distribution}

1. W. J. Allington

2-7. J. B. Andriulli

8. C. L. Coomer

9. E. T. Grostick

10. J. W. McKeever

11. D. U. O'Kain

12. R. M. Schilling

13-14. Laboratory Records

15. Laboratory Records Department-RC

\section{External Distribution}

16. R. O. Hultgren, ORNL Site Manager, Department of Energy, Oak Ridge National Laboratory, Post Office Box 2008, Oak Ridge, Tennessee 378316269

17. Office of Scientific and Technical Information, Post Office Box 62, Oak Ridge, Tennessee 37831 